\title{
MODELAGEM DE NICHO ECOLÓGICO PREVÊ DISTRIBUIÇÃO DO CARANGUEJO DE ÁGUA DOCE, FREDIUS REFLEXIFRONS (ORTMANN, 1897), NO SETOR SETENTRIONAL DO PLANALTO DA IBIAPABA - NORDESTE DO BRASIL
}

\author{
Santos, L.C. ${ }^{1}$; Nascimento, W.M. ${ }^{2}$; Macêdo, R.S. ${ }^{2}$; Pinheiro, A.P. ${ }^{2}$; Silva, J.R.F. ${ }^{1}$ \\ ${ }^{1}$ Universidade Federal do Ceará (UFC), Campus do PICl- Fortaleza - CE, \\ Laboratório de Ecologia de Ecossistemas Aquáticos- LEEA. \\ ${ }^{2}$ Universidade Regional do Cariri (URCA), Campus do Pimenta - Crato - CE. \\ Laboratório de Crustáceos do Semiárido - LACRUSE. \\ *Autor correspondente: santos.bio.79@gmail.com
}

\begin{abstract}
A modelagem de distribuição de espécies baseado em dados de presença é uma ferramenta importante tanto em estudos de ecologia quanto em estudos de conservação. Saber onde uma espécie está localizada é um mecanismo que ajuda na implementação de estratégias de conservação, principalmente quando a espécie se encontra distribuída de forma relictual. O caranguejo de água doce, Fredius reflexifrons (Ortmann, 1897), possui dois registros na literatura para o Planalto da Ibiapaba, no entanto, as características do setor setentrional possuem outros ambientes que são favoráveis à ocorrência desse caranguejo. Diante disso, este trabalho tem como objetivo realizar uma modelagem ecológica de nicho baseado em dados de presença. Os dados de presença, dois da literatura e nove de expedições no Planalto da Ibiapaba foram tabelados e submetidos ao Software Maxent, além das varáveis bioclimáticas referentes ao clima atual oriundas do grupo da DPI/OBT e recortados para o Brasil e Amazônia Legal. O modelo foi avaliado pelo valor de AUC (Área Under the ROC Curve) que varia de 0 a 1, onde 1 demonstra uma diferença máxima entre a previsão e o que seria feito ao acaso, iguais a 0,5 indicam previsões iguais realizadas ao acaso, e menores que 0,5 apontam previsões piores do que as ocorridas ao acaso; e pelo teste estatístico jacknife. O modelo gerado apresentou uma alta capacidade preditiva de 0,96 o que mostra um bom modelo de distribuição geográfica para espécies. Portanto, a distribuição desse caranguejo possui uma distribuição maior que reportada na literatura para o setor setentrional no Planalto da Ibiapaba, o que torna importante a modelagem para auxiliar na conservação da espécie nessa região.
\end{abstract}

Palavras-chave: Área Under the ROC Curve, Brachyura, máxima entropiam, semiárido nordestino. 